Voix et Images

voixetimages

\title{
Marie-Claire Blais : Une liaison parisienne
}

\section{André Vanasse}

Volume 1, numéro 3, avril 1976

\section{Gérard Bessette}

URI : https://id.erudit.org/iderudit/200048ar

DOI : https://doi.org/10.7202/200048ar

Aller au sommaire du numéro

Éditeur(s)

Les Presses de l'Université du Québec

ISSN

0318-9201 (imprimé)

1705-933X (numérique)

Découvrir la revue

Citer cet article

Vanasse, A. (1976). Marie-Claire Blais : Une liaison parisienne. Voix et Images, 1(3), 456-457. https://doi.org/10.7202/200048ar d'utilisation que vous pouvez consulter en ligne.

https://apropos.erudit.org/fr/usagers/politique-dutilisation/ 


\section{Marie-Claire Blais: Une liaison parisienne}

"Madame d'Argenti, en ce sens, était morte, il ne pourrait la faire survivre que par la littérature, et encore on lui dirait "que les romans ne sont pas comme la vie..." (p. 175)

C'est par cette phrase que se termine Une liaison parisienne, le dernier roman de Marie-Claire Blais. Phrase éminemment proustienne (MarieClaire Blais s'en réclame d'ailleurs à quelques reprises dans ce roman) et dont la dernière proposition est passablement vraie.

Comment pourrais-je passer sous silence mes oh! et/ou (sic) mes ah! à la lecture de la description des états d'âme de ce pauvre Mathieu Lelièvre, auteur d'un premier roman grâce auquel il s'imagine conquérir Paris. Inutile de préciser que Mathieu Lelièvre ne conquerra ni Paris ni le cœur d'Yvonne D'Argenti, celle qui très tôt l'utilisera à seule fin de satisfaire son insatiable appétit sexuel.

En fait deux mondes s'affrontent par le biais de ces deux personnages. Mathieu Lelièvre a quitté son Québec natal pour enfin retrouver son âme française! Parce qu'il a toujours vécu en marge de sa propre culture (il se nourrit essentiellement de littérature... française et n'a que mépris pour tout ce qui est québécois) il s'imagine connaître à fond la mentalité française. Programmé comme un robot, il ne parviendra à se libérer de sa vision distordue (et combien romantique!) de la "fine fleur de l'aristocratie française " qu'à la toute fin du roman.

D'entrée de jeu la personnalité monstrueuse d'Yvonne D'Argenti lui échappe totalement. Chaque geste ou parole de cette Messaline qui déteste de façon inhumaine ses enfants et qui, en outre, est plus ou moins responsable de la pédérastie de son mari, lui apparaît comme une énigme. Il voit bien la fausseté et la méchanceté foncières d'Yvonne D'Argenti mais prisonnier de ses phantasmes (Yvonne n'est-elle pas et française et romancière?) il s'imagine bêtement qu'il voit mal:

- Ma chère, le problème des Indes ne peut se résoudre que par la bombe atomique, voilà ce que nous devons souhaiter à ces pauvres, et croyez-moi, ils sont si vils et si paresseux qu'ils le méritent bien.

Cette déclaration, à la grande surprise de Mathieu, n'avait pas eu le pouvoir de couper le souffle à Madame D'Argenti, [...]

Était-ce donc cette même femme qui "voulait partir aux Indes secourir les malheureux» comme disait son mari? Mathieu rêvait peut-être ou il entendait de plus en plus mal. (p. 60)

Et c'est là précisément l'aspect choquant du roman. Comment accepter cette super-naïveté de la part d'un jeune romancier que l'on suppose un tantinet lucide? II y a à la fois une indéniable vérité dans cette description (les 
Québécois qui ont fréquenté les milieux «aristo" de Paris peuvent en parler d'abondance) mais en même temps une rupture dans la description (Mathieu, c'est vraiment CEdipe qui se crève les yeux avant d'avoir vu) qui en annule l'impact.

Néanmoins il faut bien admettre que Marie-Claire Blais nous livre un monde à sa mesure. Une liaison parisienne, c'est en somme Une saison dans la vie d'Emmanuel vue d'en haut. La famille D'Argenti n'a rien à envier à celle de Jean Le Maigre. Les enfants y sont traités de la même façon à cette différence près que les adultes de l'aristocratie française ont développé au cours des siècles un code de la répartie qui n'appartient qu'en propre à cette classe sociale. Ainsi Madame D'Argenti s'est bien permis de laisser tomber Paul, son fils à peine naissant, "de ses genoux au sol du marbre" (p. 74). Cela est à la portée de tout le monde... même d'un Québécois! Mais qui pourrait, quinze ans plus tard, répliquer: “Aujourd'hui si heureux de vivre, regardez-le, ce dadais, a-t-il le crâne fracassé ? Non il est seulement analphabète, ce qui est plus choquant..."! (p. 75)

André Vanasse Université du Québec à Montréal 